\title{
EFEITO DO SOMBREAMENTO NO CRESCIMENTO INICIAL DE LONCHOCARPUS MUEHLBERGIANUS HASSL
}

\author{
Maria A. Eva Cancian ${ }^{1}$ \\ Lázara Cordeiro ${ }^{1}$
}

Recebido em 12/01/1999. Aceito em 24/03/1999

\begin{abstract}
RESUMO - (Efeito do sombreamento no crescimento de Lonchocarpus muehlbergianus Hassl). Foi realizado experimento em casa de vegetação para verificar a influência do sombreamento no desenvolvimento de plantas de Lonchocarpus muehlbergianus. Foram utilizados os níveis de sombreamento de 40 e $60 \%$ com tela de sombrite de cor preta e o nível de $0 \%$, com luminosidade total. Foram obtidos os seguintes resultados: as plantas cultivadas em 40 e $60 \%$ de sombreamento apresentaram as maiores médias de altura e área foliar. Os maiores valores de diâmetro do colo e da raiz principal e de peso da matéria seca da parte aérea e do sistema radicular foram observados nas plantas sob 0 e $40 \%$ de sombreamento.
\end{abstract}

Paravras-chave - sombreamento, Lonchocarpus muehlbergianus, crescimento

\begin{abstract}
Effect of shading on the initial growth of Lonchocarpus muehlbergianus Hassl). This experiment was carried out under greenhouse conditions to verifiy the influence of shading on the growth of Lonchocarpus muehlbergianus plants. The following shading levels were used: $40 \%$ and $60 \%$ obtained using black plastic screening, and $0 \%$ under full light. The following results were obtained: the plants cultivated in $60 \%$ shading were higher and present larger leaf areas, wider collar and main root diameters, besides larger aerial and dry root weight were obtained in plants cultivated in $0 \%$ and $40 \%$ shading.
\end{abstract}

Key words - shading, Lonchocarpus muehlbergianus, growth

\section{Introdução}

A crescente demanda por espécies florestais, seja com finalidade econômica ou para atender programas de plantio, tem impulsionado os estudos que visam à obtenção de conhecimentos sobre as características silviculturais das espécies e a influência dos fatores ambientais no comportamento das mesmas.

A luz é um dos fatores ambientais que exerce influência sobre o crescimento e o desenvolvimento das plantas. O cultivo com sombreamento artificial é um método que tem sido utilizado por vários pesquisadores para a avaliação do comportamento das espécies vegetais, as quais têm mostrado diferentes respostas.

1 Departamento de Botânica, IB, UNESP, C. Postal 199, CEP 13506-900, Rio Claro, SP, Brasil 
Analisando a influência do sombreamento no desenvolvimento de mudas de Piptadenia rigida, Schizolobium parahyba e Albizzia lebbeck, Poggiani et al. (1992) observaram maior desenvolvimento em altura nas mudas produzidas sob $80 \%$ de sombreamento. Os autores verificaram que, neste nível de sombreamento, apenas as plantas de $P$. rigida apresentaram incrementos significativos no peso de matéria seca das folhas e na área foliar.

Para mudas de Dinizia excelsa, Varela \& Santos (1992) constataram decréscimo no desenvolvimento em altura, na produção de matéria seca da parte aérea e do sistema radicular e no diâmetro do colo, em função da elevação dos níveis de sombreamento (30, 50 e 70\%). Pinto et al. (1993), investigando a influência do sombreamento no comportamento de mudas de Licaria canella, verificaram que o crescimento em altura e a área foliar não foram influenciados pelos diferentes níveis de sombreamento testados $(0,30,50 \mathrm{e} 70 \%)$. As mudas produzidas em $50 \%$ de sombreamento apresentaram maiores valores de matéria seca da parte aérea e do sistema radicular.

O presente estudo teve como objetivo verificar o efeito do sombreamento no crescimento inicial de Lonchocarpus muehlbergianus (Leguminosae). A espécie é conhecida popularmente como guaianã, embira-de-sapo e feijão-cru. O seu desenvolvimento é bastante rápido, atingindo, na idade adulta, $15-25 \mathrm{~m}$ alt. A floração ocorre no período de outubro a janeiro sendo produzida, anualmente, grande quantidade de sementes viáveis. Sua madeira é empregada para tabuado em geral, carpintaria leve, caixotaria e lenha. Pode ser aproveitada para paisagismo em geral e nos plantios mistos destinados à recomposição de áreas degradadas e de preservação permanente (Lorenzi 1992).

\section{Material e métodos}

O experimento foi desenvolvido em casa de vegetação localizada no Jardim Experimental do Instituto de Biociências da Universidade Estadual Paulista, campus de Rio Claro, Estado de São Paulo.

O substrato utilizado foi uma mistura de areia e vermiculita (1:1), lavadas em água corrente e secas ao ar em temperatura ambiente. A adubação constou de: $40 \mathrm{mg}$ de $\mathrm{MgO}, 60 \mathrm{mg}$ de $\mathrm{KCl}, 10 \mathrm{mg}$ de $\mathrm{CuSO}_{4}, 2 \mathrm{mg}$ de $\mathrm{H}_{2} \mathrm{BO}_{3}, 2 \mathrm{mg}$ de $\mathrm{Na}_{2} \mathrm{MoO}_{4}, 2 \mathrm{mg}$ de $\mathrm{FeSO}_{4}, 10 \mathrm{mg}$ de $\mathrm{MnSO}_{4}, 40 \mathrm{mg}$ de $\mathrm{NH}_{4} \mathrm{NO}_{3}$ e $350 \mathrm{mg}$ de superfosfato simples/kg de substrato, estando incluídos neste último, $98 \mathrm{mg}$ de cálcio e $42 \mathrm{mg}$ de enxofre $/ \mathrm{kg}$ de substrato (Verner 1995, comunicação pessoal). Após a homogeneização dos adubos ao substrato, foram colocados $3,8 \mathrm{~kg}$ deste por vaso plástico, pintado com tinta acrílica preta, com o total de 30 vasos.

Os vasos foram divididos em três lotes iguais, dispostos sobre mesas separadas. Duas mesas receberam armações laterais de bambu com 1,5m alt., que serviram de sustentação para uma ou duas camadas de tela de sombrite preto, utilizadas na obtenção dos diferente níveis de sombreamento. A terceira mesa não recebeu cobertura. Com utilização de luxímetro Metrawatt, modelo Metrux K, foram realizadas cinco leituras da intensidade luminosa de cada ambiente, verificando-se que a média da luminosidade na casa de vegetação foi de 14.825 lux (100\% de luminosidade). Sob a camada única de tela, foi de 8.900 lux $(60,03 \%$ da luminosidade total) e sob a dupla camada de tela, 
foi de 5.875 lux (39,62\% da luminosidade total), sendo considerados como tratamento $0 \%, 40 \%$ e $60 \%$ de sombreamento, respectivamente.

As sementes de L. muehlbergianus, doadas pelo Centro de Sementes do Instituto Florestal, São Paulo, foram selecionadas quanto ao tamanho, com a finalidade de se obter maior uniformidade, desinfestadas superficialmente com álcool etílico $96^{\circ}$ G.L. por cinco minutos, seguido de hipoclorito de sódio a $10 \%$ durante cinco minutos e depois lavadas 10 vezes com água destilada esterilizada (Vincent 1970, modificado).

Foram colocadas cinco sementes/vaso. O desbaste foi realizado 24 dias após o plantio, deixando-se duas plantas/vaso. Em seguida, os vasos foram transferidos para os diferentes níveis de sombreamento. As coletas foram realizadas aos quatro e oito meses após a transferência das plantas para os diferentes níveis de sombreamentos, sendo as mesmas avaliadas quanto ao número de folhas, área foliar, extensão da parte aérea e da raiz principal, diâmetro do caule na altura do colo e diâmetro máximo da raiz principal. Os pesos das matérias secas da parte aérea e do sistema radicular foram obtidos apenas na segunda coleta (após as plantas atingirem peso constante em estufa de secagem a $60^{\circ} \mathrm{C}$ ). Para a determinação da área foliar utilizou-se medidor de área CI202 CID. Os resultados foram submetidos à análise de variância e teste de Tukey ao nível de $5 \%$ de probabilidade.

O delineamento experimental foi um fatorial de $3 \times 2 \times 10$, correspondendo, respectivamente, aos níveis de sombreamento, coletas e repetições.

\section{Resultados e discussão}

Os resultados médios do número de folhas, área foliar, extensão da parte aérea e da raiz principal, diâmetro do colo e da raiz principal são apresentados na Tab. 1 . Verifica-se que, na primeira coleta, o valor médio de área foliar das plantas cultivadas com $60 \%$ de sombreamento diferiu daquele obtido em $0 \%$, sendo, no entanto igual ao de $40 \%$. Na segunda coleta, a maior produção de área foliar foi observada no tratamento sob $40 \%$ de sombreamento. Para número de folhas, verifica-se, na primeira coleta, maior valor médio em $0 \%$ de sombreamento e na segunda coleta não ocorreram diferenças significativas entre as médias nos três níveis de sombreamento. Relacionando o número de folhas com a área foliar observa-se, na primeira coleta, que os tratamentos com menor número de folhas alcançaram maiores valores de área foliar, uma vez que estas apresentaram-se mais desenvolvidas. Esta relação não se manteve na segunda coleta. Como L. muehlbergianus é planta pioneira (Lorenzi 1992), característica de ambientes onde ocorrem alta intensidade luminosa, pode ser sugerido que, como resposta da planta à sombra, houve aumento da área foliar para compensar a menor oferta de luz, principalmente no período correspondente à primeira coleta. Maior produção de área foliar sob $70 \%$ de sombreamento foi verificada por Pedroso \& Varela (1995) em mudas de Ceiba pentandra, e por Muroya et al. (1997) em Calophyllum angulare, à semelhança dos resultados obtidos neste trabalho.

Kramer \& Kozlowski (1960) citam que o crescimento em altura é bastante sensível às condições ambientais onde as plantas são cultivadas, sendo típico as mesmas apresentarem menor altura quando cultivadas a céu aberto. Os resultados da Tab. 1 
Tabela 1. Valores médios do número de folhas, área foliar, extensão da parte aérea e da raiz principal, diâmetro do colo e da raiz principal das plantas de $L$ muehlbergianus cultivadas sob 0,40 e $60 \%$ de sombreamento. Dados obtidos aos 4 (primeira coleta) e 8 (segunda coleta) meses após a transferência das plantas para os diferentes níveis de sombreamento.

\begin{tabular}{|c|c|c|c|c|c|c|}
\hline $\begin{array}{l}\text { Sombr. } \\
(\%)\end{array}$ & $\begin{array}{l}\text { Número } \\
\text { de folhas }\end{array}$ & $\begin{array}{l}\text { Área foliar } \\
\left(\mathrm{dm}^{2}\right)\end{array}$ & $\begin{array}{c}\text { Extensão parte } \\
\text { aérea }(\mathrm{cm})\end{array}$ & $\begin{array}{l}\text { Extensão raiz } \\
\text { principal }(\mathrm{cm})\end{array}$ & $\begin{array}{l}\text { Diâmetro } \\
\text { colo }(\mathrm{mm})\end{array}$ & $\begin{array}{c}\text { Diâmetro raiz } \\
\text { principal (mm) }\end{array}$ \\
\hline \multicolumn{7}{|c|}{ Primeira coleta } \\
\hline$\overline{0}$ & $5,6 a$ & $28,67 b$ & $13,6 \mathrm{~b}$ & $65,6 a$ & $4,8 \mathrm{a}$ & $8,4 a$ \\
\hline 40 & $4,1 b$ & $36,26 \mathrm{ab}$ & $17,1 \mathrm{a}$ & $49,9 b$ & $4,5 \mathrm{a}$ & $8,1 \mathrm{a}$ \\
\hline 60 & $3,9 \mathrm{~b}$ & $44,77 \mathrm{a}$ & $18,8 \mathrm{a}$ & $39.8 \mathrm{~b}$ & $3,9 \mathrm{~b}$ & $8,3 \mathrm{a}$ \\
\hline$\overline{\mathrm{CV}}(\%)$ & 13,55 & 27,40 & 13,57 & 21,43 & 10,01 & 14,23 \\
\hline \multicolumn{7}{|c|}{ Segunda coleta } \\
\hline$\overline{0}$ & $8,3^{4}$ & $57,55 \mathrm{c}$ & $18,3 \mathrm{~b}$ & $78,7 \mathrm{a}$ & $5,1 \mathrm{a}$ & $12,3 \mathrm{a}$ \\
\hline 40 & $6,9^{a}$ & $91,36 \mathrm{a}$ & $26,4 a b$ & $54,8 \mathrm{~b}$ & $5,1 \mathrm{a}$ & $11,9 \mathrm{ab}$ \\
\hline 60 & $7,0^{4}$ & $77,48 \mathrm{~b}$ & $27,9 \mathrm{a}$ & $54,3 b$ & $4,0 \mathrm{~b}$ & $9,7 \mathrm{~b}$ \\
\hline CV (\%) & 17,82 & 14,72 & 32,97 & 25,54 & 16,89 & 20,11 \\
\hline
\end{tabular}

Valores médios seguidos de letras iguais não diferem significativamente entre si, pelo teste de Tukey, ao nível de $5 \%$ de probabilidade; $\mathrm{CV}(\%)=$ Coeficiente de variação

indicam que, nas duas coletas, os tratamentos sob $40 \%$ e $60 \%$ de sombreamento proporcionaram melhor crescimento em altura. Para o diâmetro do colo, entretanto, as maiores médias foram obtidas sob $0 \%$ e $40 \%$ de sombreamento. Em mudas de Prunus brasiliensis, foi observado maior desenvolvimento em altura com $30 \%$ e $60 \%$ de sombreamento e maior diâmetro do colo a pleno sol (Sturion 1980). O mesmo foi observado para Pinus insulares (Ferreira et al. 1981).

Quanto ao crescimento do sistema radicular, observa-se na Tab. 1 que, em ambas as coletas, as maiores médias de extensão da raiz principal foram obtidas sob $0 \%$ de sombreamento, indicando decréscimo no crescimento em função do aumento do sombreamento. Para o diâmetro da raiz principal verifica-se que, na primeira coleta, não ocorreram diferenças entre as médias. Na segunda coleta, entretanto, o maior valor médio foi alcançado pelas plantas cultivadas com $0 \%$ de sombreamento, quando comparado com $60 \%$, não sendo clara, entretanto, relação entre sombreamento e diâmetro da raiz principal nas condições desse experimento.

As médias dos dados de peso de matéria seca da parte aérea, do sistema radicular e da relação entre matéria seca da raiz e parte aérea encontram-se na Tab. 2. Analisando a influência do sombreamento na produção de matéria seca, verifica-se que a média obtida para a parte aérea em $0 \%$ diferiu daquela obtida em $60 \%$, sendo, no entanto, igual a $40 \%$. Para matéria seca do sistema radicular, os melhores resultados foram obtidos sob $0 \%$ e $40 \%$ de sombreamento. Esses resultados indicam que o sombreamento mais severo (60\%) limitou a produção de biomassa da planta. Neste caso, a maior área foliar e altura das plantas não refletiram em maior produtividade. A maior produção de matéria seca obtida nos tratamentos a pleno sol e com pouco sombreamento corresponde ao esperado de espécies heliófitas, como L. muehlbergianus. Resultados semelhantes, com espécies não heliófitas, foram obtidos por Sturion (1980), que verificou maior acúmulo de matéria seca em Prunus brasiliensis cultivada a céu aberto e com $30 \%$ de sombreamento, e por Varela \& Santos (1992) que observaram redução da matéria seca com o aumento no nível de sombreamento em Dinizia excelsa. 
Quanto à relação entre a matéria seca do sistema radicular e da parte aérea, verificase na Tab. 2 que o maior valor médio foi obtido no tratamento com $0 \%$ de sombreamento. Sturion \& Iede (1982) também verificaram para Ocotea porosa maior valor dessa relação nas plantas cultivadas a pleno sol.

Tabela 2. Valores médios de massa de matéria seca da parte aérea e sistema radicular e da relação entre massa seca do sistema radicular e parte aérea das plantas de L. muehlbergianus cultivadas sob 0,40 e $60 \%$ de sombreamento. Dados obtidos aos 8 meses (segunda coleta) após a transferência das plantas para os diferentes níveis de sombreamento.

\begin{tabular}{lccc}
\hline Somb.(\%) & $\begin{array}{c}\text { Massa seca da } \\
\text { parte aérea (g) }\end{array}$ & $\begin{array}{c}\text { Massa seca do } \\
\text { sistema radicular (g) }\end{array}$ & $\begin{array}{c}\text { Relação massa seca } \\
\text { parte aérea/massa seca } \\
\text { sistema radicular }\end{array}$ \\
\hline 0 & $3,57 \mathrm{a}$ & $8,05 \mathrm{a}$ & 2,77 \\
40 & $2,96 \mathrm{ab}$ & $7,88 \mathrm{a}$ & 2,12 \\
60 & $2,48 \mathrm{~b}$ & $4,43 \mathrm{~b}$ & 1,75 \\
\hline $\mathrm{CV}(\%)$ & 29,12 & 43,37 & \\
\hline
\end{tabular}

Valores médios seguidos de letras iguais não diferem significativamente entre si, pelo teste de Tukey, ao nível de $5 \%$ de probabilidade; $\mathrm{CV}(\%)=$ Coeficiente de variação

Os resultados obtidos no presente trabalho indicam que, embora o crescimento em altura e a produção de aérea foliar tenham sido favorecidos pelo sombreamento, o tratamento sem sombreamento favoreceu o desenvolvimento dos demais parâmetros avaliados, indicando ser o mais adequado para o crescimento inicial das plantas, podendo-se indicar a luz solar direta na produção de mudas de $L$. muehlbergianus.

\section{Agradecimentos} Autora.

Ao $\mathrm{CNPq}$, pela concessão de Bolsa de Produtividade em Pesquisa à segunda

\section{Referências bibliográficas}

Ferreira, M. G. M.; Cândido, J. F.; Silva, P. A. \& Colodette, J. L. 1981. Efeito do sombreamento e da densidade de sementes sobre o desenvolvimento de mudas de Pinus insularis Endlicher e seu crescimento inicial no campo. Revista Árvore 2(1): 53-61.

Kramer, P. J. \& Koslowski, J. 1960. Physiology of trees. McGraw-Hill Book Company, New York.

Lorenzi, H. 1992. Árvores brasileiras: Manual de identificação e cultivo de plantas arbóreas nativas do Brasil. Ed. Plantarum, Nova Odessa.

Muroya, K.; Varela, V. P. \& Campos, M. A. A. 1997. Análise de crescimento de mudas de jacareúba (Calophyllum angulare A. C. Smith - Guttiferae) cultivadas em condiçōes de viveiro. Acta Amazonica 27(2): 197-212.

Pedroso, S. G. \& Varela, V. P. 1995. Efeito do sombreamento no crescimento de mudas de sumaúma (Ceiba pentandra (L.) Gaertn). Revista Brasileira de Sementes 17(1): 47-51.

Pinto, A. M.; Varela, V. P. \& Batalha, L. F. P. 1993. Influência do sombreamento no desenvolvimento de mudas de louro pirarucu (Licaria canella (Meissn.) Kosterm). Acta Amazonica 23(4): 397-404.

Poggiani, F.; Brunt, S. \& Barbosa, E. S. Q. 1992. Efeito do sombreamento sobre o crescimento de mudas de três espécies florestais. Pp. 564-569. In: Anais do $2^{\circ}$ Congresso Nacional sobre Essências Nativas, São Paulo.

Sturion, J. A. 1980. Influência da profundidade da semeadura, cobertura do canteiro e sombreamento na formação de mudas de Prunus brasiliensis Schott ex Spreng. Boletim de Pesquisa Florestal 1: 50-68. 
Sturion, J. A. \& Iede, E. T. 1982. Influência da profundidade da semeadura, cobertura do canteiro e sombreamento na formação de mudas de Ocotea porosa (Nees). Silvicultura 28: 513-516.

Varela, V. P. \& Santos, J. 1992. Influência do sombreamento na produção de mudas de angelim pedra (Dinizia excelsa Ducke). Acta Amazonica 22(3): 407-411.

Vincent, J. M. 1970. A manual for the practical study of root nodule bacteria. Blackwell Scientific Publ., Oxford. 